\title{
From Office of Research to Office of COVID Response \& Field Research in the Time of COVID
}

\author{
John P. Carroll, PhD, Director and Professor, School of Natural Resources \\ Bob Wilhelm, PhD, Vice Chancellor for Research and Economic Development \\ University of Nebraska-Lincoln
}

$\mathrm{T}$

The COVID-19 pandemic of 2020 through the current time has presented broad and new challenges for all of society. Research universities have been faced with many new demands and obstacles across all aspects of their operation. Field research, an activity that must commonly plan for disruptions and unexpected events, has had to be approached with even more creative and responsive efforts. Given that field research comprises a significant portion of the research portfolio at the University of Nebraska - Lincoln (UNL), the pandemic response at UNL and the response for continued field research are highly connected and strongly informed by each other.

This paper describes the broad response that UNL took in operating safely during the pandemic and the particular challenges of pursuing field research. In the following sections the university-wide response is first summarized. More detailed information and discussion are then presented regarding field research during the pandemic. Conclusions reflect on the effectiveness of the UNL approach and the way that university operations and field research were connected and informing.

The Broad Response of UNL to Safe Operations During the COVID-19 Pandemic

Early information about theCOVID-19 virus was visible in news services as early as January 2020. Most activity in January focused on monitoring and some risk assessment for foreign travelers. The university opened as scheduled for the spring 2020 semester and operated much the same as past years. During February, organizing began within the university to manage return travel for all faculty and students outside the country. In early March, planning accelerated for different approaches to university operations. By mid-March, the university moved to remote operations for all activities.

The pandemic response at UNL was organized early to address all aspects of a research university. A campus-wide COVID-19 task force was formed, and it began coordinating a number of specialized committees to address academics, engagement, research, facilities, events, etc. In addition to committee assignments, the leadership and staff of the Office of Research were tasked with a number of new operational duties. This led to double assignments beginning in March 2020 and continuing through the present.

As the events of the pandemic unfolded, UNL first imposed very strong restrictions on campus presence, moving all academic programs to remote operations, curtailing all events and in-person engagement activity, and reducing in-person research activities to a minimum set of critical operations. Facilities management and other operations of the university were handled remotely when possible and by a small group of on-site personnel as required. The spring semester was completed with $100 \%$ remote instruction and minimal research activity at campus sites.

During May 2020, the university began organizing for further resumption of safe on-site activities and a proactive safety plan for the fall 2020 semester. An additional committee called Forward-to- 
Fall was formed to undertake this task. The committee made use of regional and national expertise to develop a layered approach for safety and began working very closely with the regional public health department. The Forward-to-Fall plan depended heavily on the committees already supporting the COVID-19 response. In preparation for the fall semester, COVID-19 testing resources were organized in coordination with the State of Nebraska, and an integrated approach for contact tracing was developed in partnership with the Lincoln Lancaster County Health Department. A dashboard system was instituted to allow for monitoring of COVID-19 effects at the UNL campus.

During the summer of 2020, the Research Task Force worked with various research leaders to organize an approach for limited research activity that depended on detailed safety plans and significantly reduced density of people at campus research sites. Most all research activities returned to operation via these safety plans. Additional requirements were put in place for human subject research.

The fall 2020 semester opened slightly early with a new calendar that concluded the semester early as well. The majority of courses were offered with in-person options and research activity continued at campus sites with reduced density. Planning was also initiated for spring semester with initial emphasis on large-scale testing. The fall 2020 semester completed successfully and was followed by two shorter course periods in December and January.

The spring 2021 semester was scheduled to begin later and end earlier than previous years. By January 2021, UNL had created a large-scale saliva testing system for COVID-19 monitoring and increased the sophistication of the integrated contact tracing efforts. Planning also began to support vaccination of com- munity and university populations. The spring 2021 semester completed successfully. At the time of this paper, planning is underway for continued operation of the university through the fall of 2021.

All of the planning and management of the UNL COVID-19 response has been made with a small number of principles in mind. Most importantly, the campus-wide committees and task forces have offered guidance with the expectation that a larger number of leaders and experts-distributed throughout the university-are empowered to make local decisions. The campus-wide groups have been formed with an inclusive composition of campus leaders, faculty, staff, and students. The approach of guidance and distributed management has governed operations in key areas: academic planning, budget, campus operations, research, student life, health, legal, international, information technology, and campus communications. This structure was created to enable a clear chain of command while fostering bi-directional communication. Quick communication was encouraged, supported, and expected to support the rapidly changing operations approaches that have evolved from spring 2020 to the present. Finally, there has been a persistent effort among the campus leaders to plan carefully, communicate clearly, and lead both authoritatively and optimistically.

Field Research: Challenges and Learning During the Pandemic

The pandemic impacts on university operations were far reaching and required multiple levels of planning and mitigation. Field activities, especially research, provide some unique contrast to the sorts of planning that needed to be done for on-campus activities ranging from teaching to lab-based research. Interestingly, field research of all types often has far larger components of externalities that make the levels of uncertainty surrounding the research much more 
vulnerable to perturbations in systems and other factors outside of the control of the researchers. Research outside the constraints of a university campus is often accompanied by elevated risk to the research and researchers (Williams et al., 1992). ${ }^{1}$ Although we commonly think of field research in the context of certain fields of endeavor, in reality a wide range of academic disciplines-from the biological and physical sciences to anthropology, sociology, and public healthshare many common potential issues due to the nature of the disciplines.

Although on-campus and off-campus researchers may face similar types of outside factors, often the vulnerability of the research and researchers is much greater when the security of campus is left behind. For example, crop research, like the important corn and soybean work being done at UNL, often faces broad weather vagaries within a growing season despite our desire to control variability of conditions. Any researcher undertaking field work on these crops faces uncertainty every year that the whole program can be significantly and negatively impacted by a simple weather event, such as a hailstorm. A short, but by no means inclusive, range of factors that has severely impacted research programs for field-based faculty and staff includes natural disasters such as floods and earthquakes, human impacts such as public interference with study areas or organism, criminal behavior and theft, threats against personnel, and political upheaval (Grimm, 2017; Paterson et al., 1999; Phalen, 2017). ${ }^{2,3,4}$ Even within teams, the fact that research teams are often located in areas without the support network of the university can create dynamics that increase the uncertainty of smooth data collection and/or safety for personnel.

Despite the need and often preparedness of field researchers for all potential contingencies, there are few times in history, at least in U.S. history, where the ex- ternal forces have caused such a "perfect storm" of conditions.

\section{COVID and Field Research}

Over the last 18 months of the pandemic, what has become clear is that many of us who undertake field research and our institutions were not as prepared to deal with the "COVID disaster" as our risk management planning might have led us to believe. In part, our risk and emergency planning often focuses on two areas that created weaknesses in our response to this emergency. We tend to focus on risk and emergencies as incidents rather than processes. So our planning focuses on preparing for an incident, responding during the incident, and then recovering. Temporal scales are more of a point in time rather than something covering a long period of time. In addition, geographical scales of incidents can range from local, where a researcher might have to deal with field issues, to regional, where research sites are destroyed or research interrupted by a major disaster, such as a hurricane (Beggan, 2010). ${ }^{5}$

With the COVID-19 pandemic we found ourselves in a situation beyond the typical incident type of timeline and a geographical scale that was global. Contrary to most incident-based events, COVID-19 resulted in research shutdowns over long periods of time and over very large geographical areas. Among field researchers our experience was that there was a range of underlying factors that impacted the ability of the research enterprise to continue.

As the pandemic unfolded in middle America, universities scrambled to assess how to respond. Broadly there were often two groups of responses, depending on whether activities were on campus or off campus. In many cases, like our university, the off-campus work was effectively "paused" for an extended time. In most cases, allowable research activities off campus were phased in. For example, at UNL, very restrictive travel to 
local and within state research sites was allowed and then over time followed by even more restrictive requirements for traveling beyond state political boundaries. That was then followed by allowance of some research activities on an international basis.

Scale was important because ownership of locations where research was being undertaken, along with political boundaries, resulted in a variety of rules and lockdowns that were implemented in a fluid way at best. Layered on top of accessibility were rules that also dictate how research can be done, including guidelines on human (IRB) and animal (IACUC) use in research and welfare considerations for both groups. Animals in confined situations outside campus-based facilities and wild animals that might have already undergone treatments or incorporation into research projects were particularly problematic in balancing risk and welfare of the subject and the researchers. In addition, calendar-sensitive research resulted in difficult decisions on whether research activities should be suspended all together versus some dispensation for allowing minimal activity. Here at UNL, animal welfare dictated that care of research animals on a number of properties take priority. In addition, wild animals already included in field research prior to the pandemic required prioritization of data collection while most projects where paused. On many of our crop sites, research fields were planted with permission to allow a growing season to proceed in case conditions changed enough to allow data collection in light of the uncertainty of how the pandemic would unfold. Of particular concern during the pandemic were operational entities within our research portfolio that require off-campus data harvesting from multiple sites. Many universities now manage weather $\mathrm{Me}$ sonet systems, and here at UNL we also manage the groundwater well monitor- ing system for Nebraska. Those systems require uninterrupted management and data flow for both contractual and legal obligations, but also as part of networks that feed into a range of societal decision-making processes. For example, in a highly irrigated state like Nebraska, agricultural producers depend on those data systems to make decisions about irrigation scheduling.

Finally, the most critical component of the university research enterprise is the workforce. The pandemic impacted segments of the workforce in broadly different ways. The most vulnerable of these segments identified were graduate and post-doc students. Most of these individuals are in positions that are time dependent and tied to contractual responsibilities. These are followed by staff who oftentimes at universities feel they are most expendable. Stress related to workplace uncertainty also raises the issue of mental health of the workforce (Sharma et al., 2020). ${ }^{6}$ Again, communication was critical in our programs with flexibility for decision making at the local level to develop strategies allowing the lowest possible impact on research tied to education, but also assuring staff that budget considerations would prioritize active personnel above other potential cuts. These steps during periods of great uncertainty allowed morale to be maintained and allowed us to reengage research very quickly as conditions improved.

\section{Conclusion}

Although field researchers often have experience and training in dealing with a wide range of risk factors and disasters, that experience is much more focused on local and project-specific factors. COVID-19 is simply at a spatial scale that is unprecedented. In addition, risk planning is much more of a short-term incident focus whereas COVID is over a much longer time frame and one that resulted in no "end" date to the disaster. In 
effect, risk management for this pandemic is probably more analogous to climate risk management than typical disaster planning (Jones and Preston, 2011). ${ }^{7}$

Despite the lack of strategic planning for a disaster of this magnitude, we developed adaptive strategies during the pandemic that resulted in minimizing impact on researchers while ensuring safety of faculty, staff, and students-at the same time creating a sense of confidence that the university was supporting our team in allowing work to proceed in a safe manner.

Strategies adopted at UNL that we believe helped us cope with the pandemic more effectively include communication flow in both directions between researchers and upper administration; implementation of broad policy decisions by upper administration, allowing flexibility at program levels to account for the broad variability of conditions and needs; and flexibility to adjust over time to changing conditions. There was also the recognition that pausing research dramatically impacts different members of our re- search enterprise in different ways. For example, although senior faculty might have their research impacted by a pause, graduate students and post-docs had their careers impacted in a much more direct way. Assurances of accommodation, especially for students who were delayed coming to UNL, and a support network, including salary support, gave students the confidence that they could continue their programs and instilled trust in university leadership.

Within the university research community, field researchers have a history of working with a much broader range of risk factors beyond the boundaries of the university campus. A possible solution model might be found in the adoption of risk management teams now found at many universities for dealing with risk management associated with international research and other travel. As a model for developing risk planning, these committees assist researchers in weighing cost, benefits, and risk in a strategic way before international work takes place.

\section{References}

1. Williams, T., Dunlap, E., Johnson, B. D., \& Hamid, A. (1992). Personal safety in dangerous places. Journal of Contemporary Ethnography, 21:343-374.

2. Grimm, D. (2017). PETA targets early career wildlife researcher. Science, 357:1087.

3. Paterson, B. L., Gregory, D., \& Thorne, S. (1999). A protocol for researcher safety. Qualitative Health Research, 9:259-269.

4. Phalen, R. F. (2017). Core ethics for health professionals. Springer International. Cham, Switzerland, 152pp.

5. Beggan, D. N. (2010). The impact of Hurricane Rita on an academic institution: lessons learned. Disasters, 34:93-111.

6. Sharma, M. K., Anand, N., Singh, P., Vishwakarma, A., Mondal, I., and Kholi, T. (2020). Researcher burnout: an overlooked aspect in mental health research in times of COVID-19. Asian Journal of Psychiatry, 54:102367.

7. Jones, R. N., \& Preston, B. L. (2011). Adaptation and risk management. WIREs Climate Change, 2:296-308. 